\title{
Application of Ethylcellulose Coating to Hydrophilic Matrices: A Strategy to Modulate Drug Release Profile and Reduce Drug Release Variability
}

\author{
Raxit Y. Mehta, ${ }^{1}$ Shahrzad Missaghi, ${ }^{1,2}$ Sandip B. Tiwari, ${ }^{1}$ and Ali R. Rajabi-Siahboomi ${ }^{1}$
}

Received 5 December 2013; accepted 11 April 2014; published online 22 May 2014

\begin{abstract}
Hydrophilic matrix tablets are commonly used for extended release dosage forms. For low aqueous-solubility drugs, there may be challenges in modulation of release profiles and achieving consistent release in physiological conditions. To evaluate potential formulation strategies, matrix tablets of a low-soluble drug, hydrochlorothiazide, were developed using hypromellose and two fillers of different solubility, lactose (soluble) or partially pregelatinized maize starch (partially soluble). Additionally, application of an insoluble barrier membrane, aqueous ethylcellulose coating system, and a hydrophilic pore former onto matrix tablets was evaluated. Drug release from uncoated matrix tablets was variable at different agitation rates. Evaluation of tablets in bio-relevant media using physiologically relevant residence time indicated variable and higher initial release rate for uncoated matrices containing lactose but more robust behavior for tablets containing partially pregelatinized starch. Such in vitro behavior may lead to erratic drug release in vivo, when comparing fed versus fasted conditions. Dissolution profiles from barrier membrane-coated tablets showed initial delay, followed by zero-order release kinetics, with reduction or elimination of variability compared to uncoated matrices. Such reduced variability may mitigate mechanical effects of post-prandial stomach. Effects of coating weight gain and inclusion levels of pore former were evaluated and found to be critical in achieving robust and stable release profiles.
\end{abstract}

KEY WORDS: bio-relevant media; drug release variability; ethylcellulose coating; hydrophilic matrix tablets; hypromellose.

\section{INTRODUCTION}

Hydrophilic matrix technology has been widely used for oral controlled delivery of various drugs. The advantages of this technology are ease of formulation, cost-effective manufacturing process, wide regulatory acceptance of the polymer systems, and flexibility in the control of the drug release profiles. Hypromellose (hydroxypropyl methyl cellulose, HPMC) is the most commonly used polymer in formulation of extended release (ER) hydrophilic matrix tablets. When a hydrophilic matrix dosage form is exposed to the gastrointestinal (GI) fluid, the polymer on the surface of the dosage form hydrates and swells, forming a protective gel layer from which the drug is gradually and continuously released over time, either by diffusion through the polymeric gel layer, by erosion of the gel layer, or by a combination of these mechanisms $(1,2)$.

The key to optimal formulation design for hydrophilic matrix systems is the formation of a robust gel structure which enables consistent drug release, irrespective of the changes in

Electronic supplementary material The online version of this article (doi:10.1208/s12249-014-0128-5) contains supplementary material, which is available to authorized users.

${ }^{1}$ Global Headquarters, Colorcon, Inc., 275 Ruth Rd., Harleysville, Pennsylvania 19438, USA.

${ }^{2}$ To whom correspondence should be addressed. (e-mail: SMissaghi@ colorcon.com) the GI tract. The major factors governing formation and strength of the gel layer are the chemistry, viscosity grade, concentration, and particle size of the hydrophilic polymer. In the case of a low aqueous-solubility drug, where the drug release is predominantly controlled by erosion of the polymeric gel layer, low viscosity grades of hypromellose (e.g., METHOCEL ${ }^{\text {TM }}$ K100LV premium cellulose ethers) are generally recommended to achieve complete and consistent drug release from matrix tablets. Low inclusion level of such grades of hydrophilic polymers, however, may contribute to lower gel strength (3) and further result in variable and inconsistent release for some drugs. This effect could be critical when matrix tablets are exposed to the post-prandial stomach. The physiological environment of the stomach (i.e., presence of food, mechanical forces, location of matrix tablets within or on the surface of stomach content, availability of the hydrating liquid, effect of acid secretion, and residence time) may alter the motility and transit time of the dosage forms through the GI tract. As a result of the peristaltic action of the stomach, matrix tablets could be subjected to intensified shear forces for an extended period of time, which may change the erosion pattern of the hydrophilic polymer and lead to an undesirable increase in drug release. For matrix tablets of low-soluble drugs, it is important to accurately predict such effects and to modulate and achieve consistent release using the compendial dissolution testing. In some cases the variation in the agitation rate may be a useful approach to simulate the excessive mechanical stress observed in the fed state (4-7). In addition, the 
Table I. Composition of Extended Release Hydrochlorothiazide Matrix Tablets

\begin{tabular}{|c|c|c|c|}
\hline \multirow{2}{*}{$\frac{\text { Ingredients }}{\text { Hydrochlorothiazide (HCTZ) }}$} & \multirow{2}{*}{$\frac{\text { Supplier }}{\text { Hubei Maxpharm, China }}$} & \multicolumn{2}{|c|}{ Composition $(\% w / w)$} \\
\hline & & 50.0 & 50.0 \\
\hline Hypromellose (METHOCEL ${ }^{\mathrm{TM}}$ K100LV Premium CR) & The Dow Chemical Company, USA & 30.0 & 30.0 \\
\hline Lactose monohydrate (FastFlo) & Foremost, USA & - & 19.0 \\
\hline Partially pregelatinized starch (Starch 1500) & Colorcon, USA & 19.0 & - \\
\hline Colloidal silica (CAB-O-Sil@ M5P) & Cabot Corp., USA & 0.5 & 0.5 \\
\hline Magnesium stearate & Mallinckrodt, USA & 0.5 & 0.5 \\
\hline Total & & 100.0 & 100.0 \\
\hline
\end{tabular}

change of $\mathrm{pH}$ and/or ionic strength of the media as well as the use of fed and fasted simulated media (FaSSIF and FeSSIF) can provide better insight as to the fate of the hydrophilic matrix tablets in the GI tract (8-13).

The initial approach to achieve a robust matrix system is to use an optimal concentration of the rate controlling polymer and obtain consistent gel formation. Moreover, inclusion of excipients, such as partially pregelatinized maize starch (Starch 1500®) can enhance the strength of the gel layer and prevent premature erosion of the hydrated matrix tablets (14). In addition, the application of an insoluble barrier membrane coating over hydrophilic matrices has been utilized as an approach to modulate drug release from matrix tablets by attaining zero-order drug release kinetics (15). The presence of a barrier membrane coating may also provide protection against shear forces observed in the post-prandial stomach and offer consistent drug release throughout the GI tract.

To further explore the utility of this approach, the objective of the present study was to investigate the application of a barrier membrane coating, containing ethylcellulose, and a pore former, onto matrix tablets of a very low-soluble model drug, hydrochlorothiazide. The combination of barrier membrane and hydrophilic matrix system was utilized as a strategy to modulate drug release from hydrophilic matrices and to reduce the overall variability in release. Such variability was associated with the difference in drug release upon changing

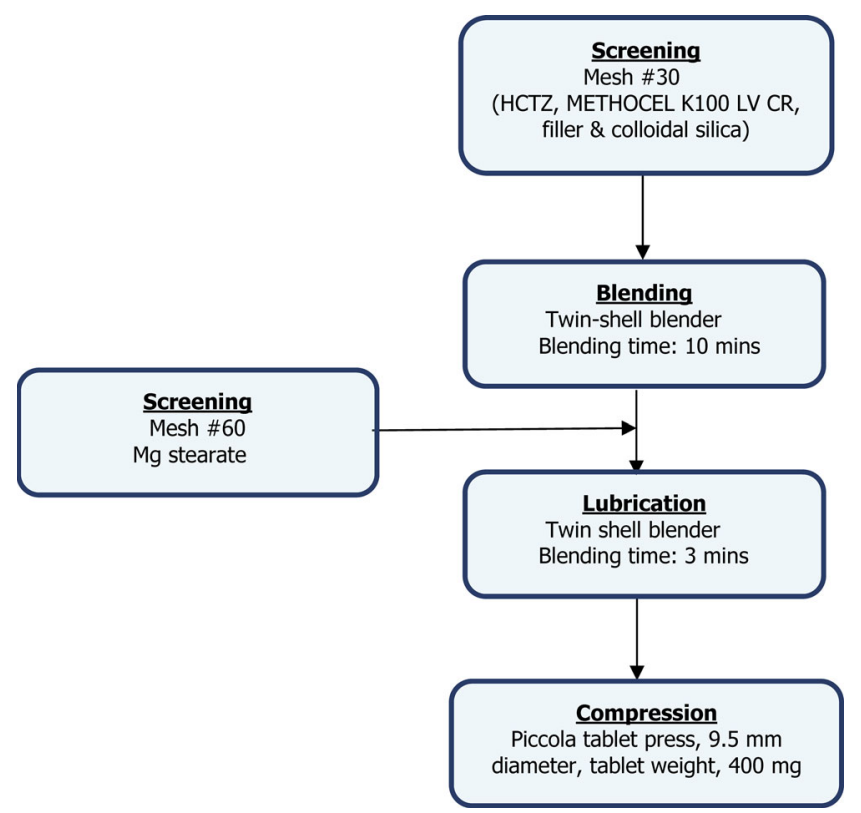

Fig. 1. Process flow chart for production of HCTZ matrix tablets the agitation rate within the dissolution media. The influence of coating weight gain and pore former level within the coating was also investigated. In conjunction with the coating, the effect of filler type within the core formulation of matrix tablets was also evaluated. Furthermore, in order to evaluate the performance of the ethylcellulose coated matrices over time, the tablets were subjected to stability testing under different ICH storage conditions.

\section{MATERIALS AND METHODS}

\section{Tablet Formulation and Manufacture}

In this study, hydrochlorothiazide (HCTZ), a very slightly water-soluble diuretic compound $(\sim 0.7 \mathrm{mg} / \mathrm{ml})$ (16) was used as a model drug at the dose level of $200 \mathrm{mg}$. The composition of hydrochlorothiazide ER matrix tablets is shown in Table I. HCTZ, HPMC (METHOCEL K100LV Premium CR), filler (Starch 1500 or lactose) and colloidal silicon dioxide were

Table II. Fasted State Dissolution Testing in USP Apparatus III

\begin{tabular}{lccc}
\hline Vessel & Media (pH) & $\begin{array}{c}\text { Residence } \\
\text { time (min) }\end{array}$ & $\begin{array}{c}\text { Sampling } \\
\text { time (min) }\end{array}$ \\
\hline 1 & FaSSGF (1.8) & 60 & 60 \\
2 & FaSSIF (6.5) & 15 & 75 \\
3 & FaSSIF (6.8) & 15 & 90 \\
4 & FaSSIF (7.2/halved & 30 & 120 \\
5 & bile salts) & & 240 \\
6 & Blank FaSSIF (7.5) & 120 & $360,480,600$, \\
& Blank FaSSIF (6.5) & 720 & $720,840,960$ \\
\hline
\end{tabular}

Table III. Fed State Dissolution Testing in USP Apparatus III

\begin{tabular}{lccc}
\hline Vessel & Media (pH) & $\begin{array}{c}\text { Residence } \\
\text { time (min) }\end{array}$ & $\begin{array}{c}\text { Sampling } \\
\text { time (min) }\end{array}$ \\
\hline 1 & Ensure® plus (6.4) & 120 & 120 \\
2 & FeSSIF (5.0) & 45 & 165 \\
3 & FeSSIF (6.5) & 45 & 210 \\
4 & FeSSIF (6.5/halved & 45 & 255 \\
& bile salts) & & \\
5 & Blank FaSSIF (7.5) & 45 & 300 \\
6 & Blank FaSSIF (6.5) & 720 (pull & $420,540,660$ \\
& & every 120) & $780,900,1020$ \\
\hline
\end{tabular}


Uncoated Matrix Tablet:

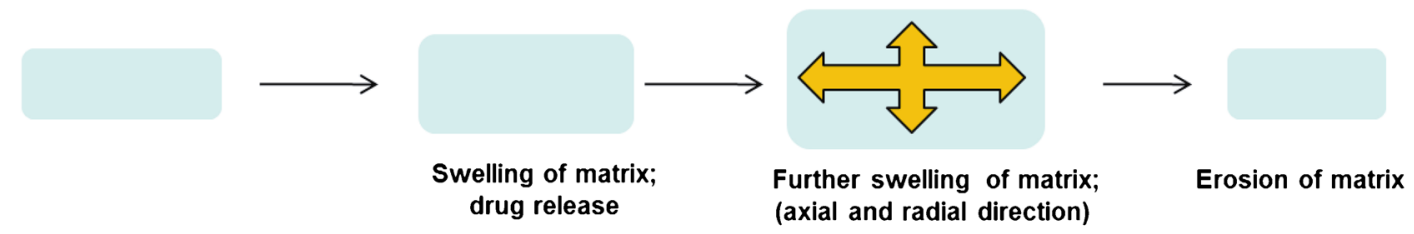

Ethylcellulose Coated Matrix Tablet:

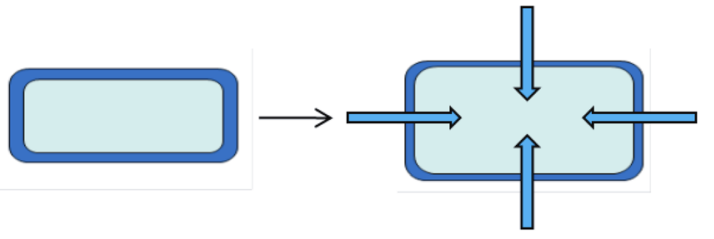

Swelling of matrix due to water permeation

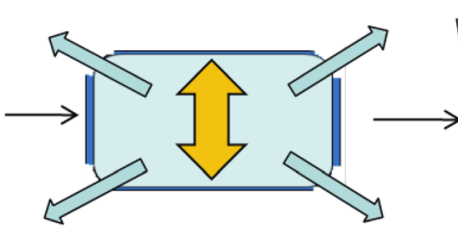

Rupture of barrier membrane; release of drug from tablet edges

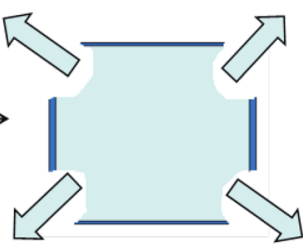

Erosion of matrix
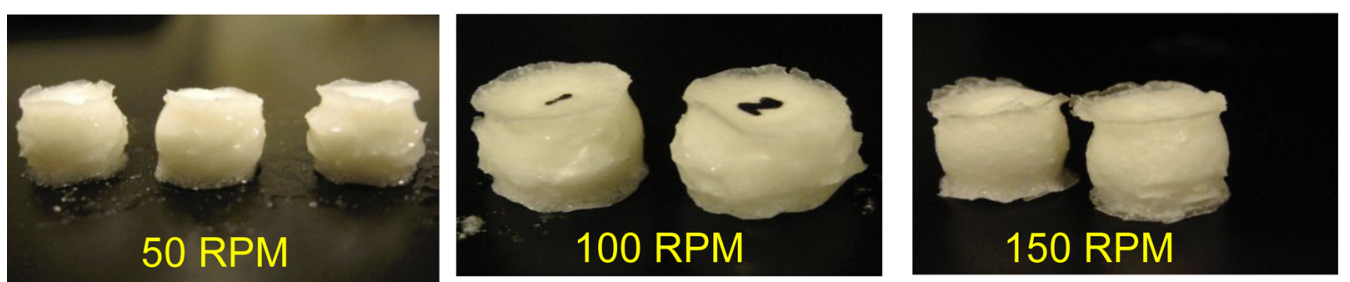

Fig. 2. Fate of uncoated and aqueous ethylcellulose coated matrices in dissolution media (tablet images show ethylcellulose coated matrix tablets)

sieved through a screen, US-standard mesh \#30 (600 $\mu \mathrm{m})$, added to a twin-shell blender (Patterson-Kelley, USA), and mixed for $10 \mathrm{~min}$. The powder blends were then lubricated with magnesium stearate for $3 \mathrm{~min}$ and compressed on an instrumented rotary tablet press (Piccola, Riva, Argentina) using standard concave tooling $(9.5 \mathrm{~mm})$ at a target tablet weight of $400 \mathrm{mg}$ (Fig. 1). Matrices with tablet hardness greater than $15 \mathrm{kp}(3.4 \mathrm{MPa})$ were used for application of ethylcellulose coating as an insoluble barrier membrane.

\section{Application of Ethylcellulose Coating}

Matrix tablets of HCTZ were coated with an insoluble barrier membrane (BM) using aqueous ethylcellulose coating, Surelease ${ }^{\circledR}$ (containing medium chain triglyceride as

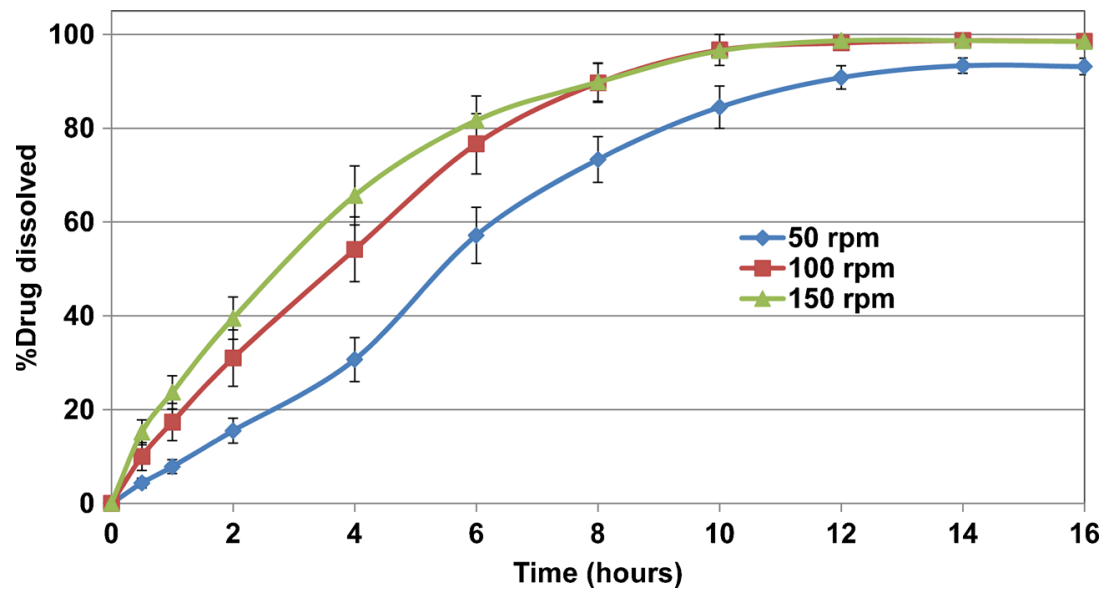

Fig. 3. Drug release profiles of uncoated HCTZ matrix tablets containing lactose, as filler, in compendial media at different agitation rates 


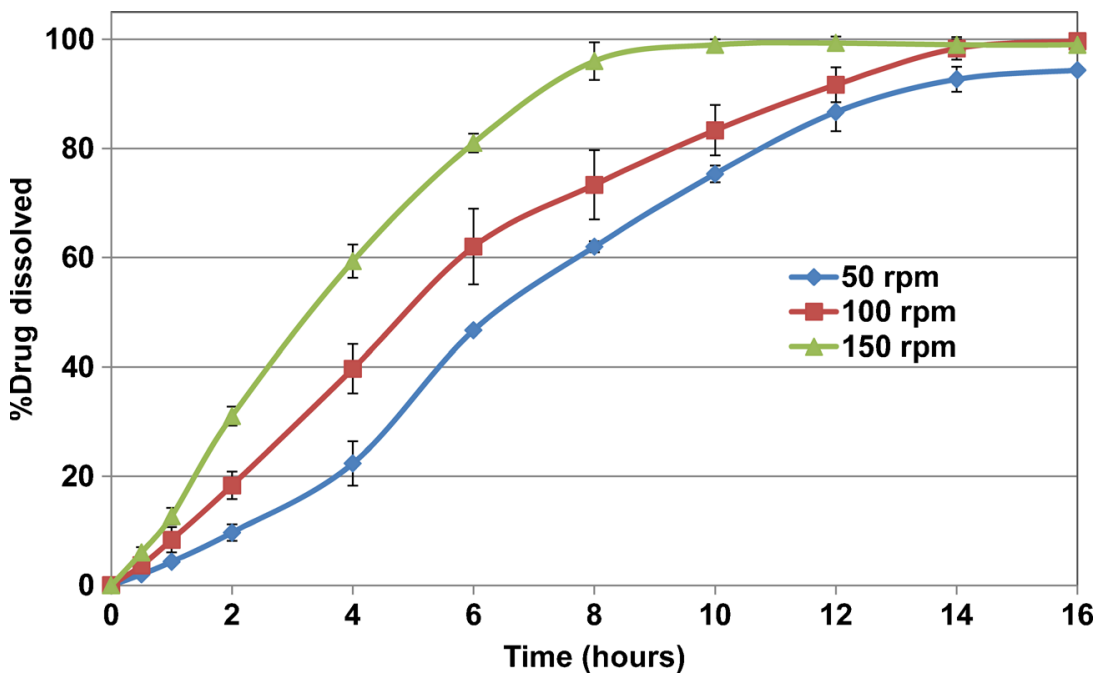

Fig. 4. Drug release profiles of uncoated HCTZ matrix tablets containing Starch 1500, as filler, in compendial media at different agitation rates

plasticizer) and an HPMC-based Opadry® (HPMC low viscosity grade, $6 \mathrm{cps}$, triacetin, and talc) as a pore former, at $85: 15$ and 60:40 $w / w$ ratios. The ratio of Surelease to Opadry was calculated based on total dry solids. Prior to application, the coating systems were dispersed in water at $10 \% \mathrm{w} / \mathrm{w}$ solids content. Tablets (batch size, $1 \mathrm{~kg}$ ) were then coated to $2 \%-8 \%$ $w / w$ weight gain (WG) in a fully perforated coating pan (LABCOAT I, O'Hara Technologies, Canada) using a 1-mm nozzle (970/7-1S75, Schlick, Germany). Standard coating processing parameters were used for application of aqueous ethylcellulose barrier membrane coating (i.e., product temperature, $42^{\circ} \mathrm{C}-45^{\circ} \mathrm{C}$; spray rate of $6-8 \mathrm{~g} / \mathrm{min}$; air flow of $\left.290 \mathrm{~m}^{3} / \mathrm{h}\right)$.

It is generally known that organic application of ethylcellulose coating can result in stronger film compared to the aqueous system. For comparison, the HCTZ matrix tablet cores containing lactose were also coated using a combination of ethylcellulose (ETHOCEL TM Standard 20 Premium) and hypromellose (METHOCEL E5LV) (The Dow Chemical
Company, USA), as a pore former, at 85:15 and 60:40 $w / w$ in a solvent mixture of isopropanol and water, $90: 10 \mathrm{w} / \mathrm{w}$, at $7 \%$ solids content.

\section{Drug Release Study}

The uncoated and ethylcellulose coated matrix tablets were subjected to dissolution testing in different media $(n=$ 3-6), as outlined below to mimic fed and fasted conditions and compare the dissolution performance of the tablets. The drug release profiles were compared using similarity factors $\left(f_{2}\right)$, where $f_{2}$ values of 50 to 100 indicate similarity in drug release between the evaluated tablets (23).

\section{Compendial Media}

Drug release testing of HCTZ matrix tablets were conducted using USP apparatus II, paddles, (Agilent Technologies, Cary, USA) with sinkers and $900 \mathrm{ml}$ of dissolution media

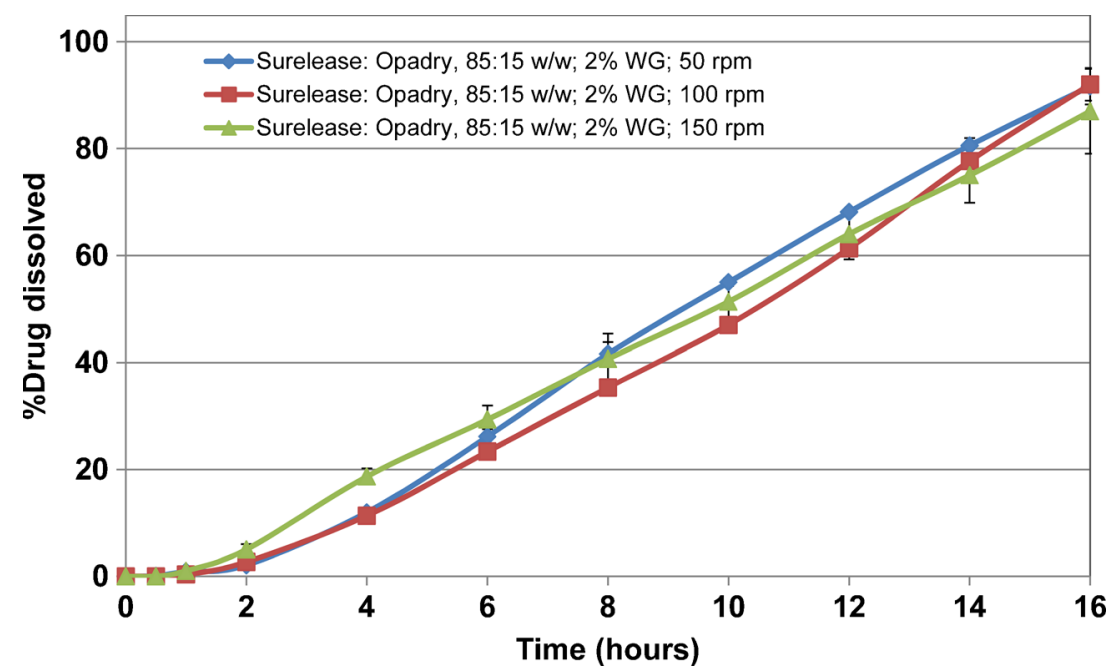

Fig. 5. Drug release profiles of aqueous ethylcellulose coated HCTZ matrix tablets containing lactose in compendial media (coated with Surelease/Opadry, 85:15 w/w, 2\% $w / w$ weight gain (WG)) 


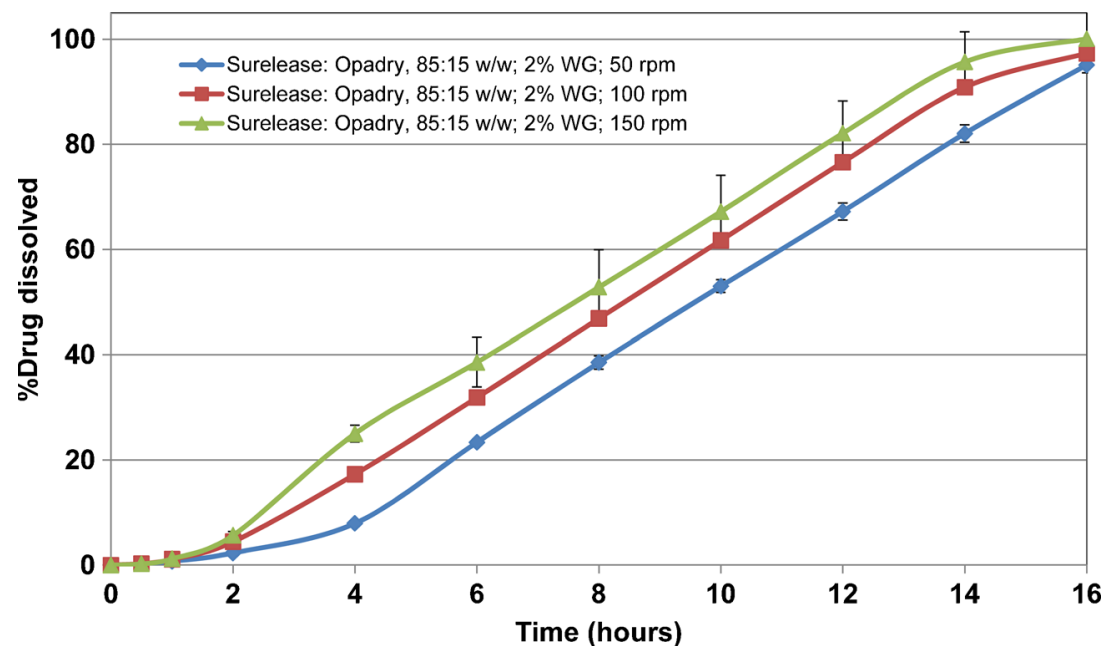

Fig. 6. Drug release profiles of aqueous ethylcellulose coated HCTZ matrix tablets containing Starch 1500 in compendial media (coated with Surelease/Opadry, 85:15 w/w, 2\% w/w weight gain $(\mathrm{WG})$ )

at $37^{\circ} \mathrm{C} \pm 0.5^{\circ} \mathrm{C}$. The fed state was simulated using a two-stage dissolution method. The tablets were first exposed to acetate buffer, $\mathrm{pH} 4.5$, for $4 \mathrm{~h}$, followed by phosphate buffer, $\mathrm{pH} 6.8$, (at $100 \mathrm{rpm}$ ) for the remainder of the test $(12 \mathrm{~h})$. The elevated mechanical stress observed in the fed stomach was simulated by varying the agitation rates during the first stage of dissolution testing at 50, 100, and $150 \mathrm{rpm}$. The HCTZ release was determined using a UV/Vis spectrophotometer (Cary 50, Agilent technologies, USA) at a wavelength of $272 \mathrm{~nm}$.

\section{Bio-Relevant Media}

Dissolution testing was performed using USP apparatus III, reciprocating cylinder, (BIO-DIS, Agilent Technologies, Cary, USA) at $37^{\circ} \mathrm{C}$. The bio-relevant dissolution media, FaSSIF phosphate buffer, FeSSIF acetate buffer, FaSSIF, and FeSSIF were prepared according to Phares SIF Powder Preparation Protocol. Ensure Plus was used directly as purchased with no modification $(9,10)$. The reciprocating cylinder was operated at 10 dips per minute (dpm) with multiple steps of media change over to simulate the human gastrointestinal environment. The media loading sequence for USP apparatus III is described in Tables II and III (11). All samples were diluted at 1:10 ratio using HPLC mobile phase (0.1-M sodium phosphate buffer/acetonitrile, 90:10, $\mathrm{pH} 3.0$ ) prior to injection. Sample solutions $(0.08 \mathrm{mg} / \mathrm{ml} ; 20 \mu \mathrm{L})$ were injected into the HPLC system and analyzed using a UV/Vis detector (Waters 2695 Alliance System, USA). Separation was performed on a Waters Symmetry $\mathrm{C}_{18}$ Column $(4.6 \mathrm{~mm} \times 75 \mathrm{~mm} \times 3.5 \mu \mathrm{m})$ at the column temperature of $30^{\circ} \mathrm{C}$ and UV detection wavelength of $254 \mathrm{~nm}$. The mobile phase was pumped isocratically at a flow rate of $1.5 \mathrm{ml} / \mathrm{min}$.

\section{Stability Study}

The HCTZ matrix tablets coated with Surelease and Opadry pore former were subjected to stability study. The tablets were packaged in HDPE bottles with desiccant, heat sealed, and stored at $30^{\circ} \mathrm{C} / 65 \% \mathrm{RH}$ and $40^{\circ} \mathrm{C} / 75 \% \mathrm{RH}$ for

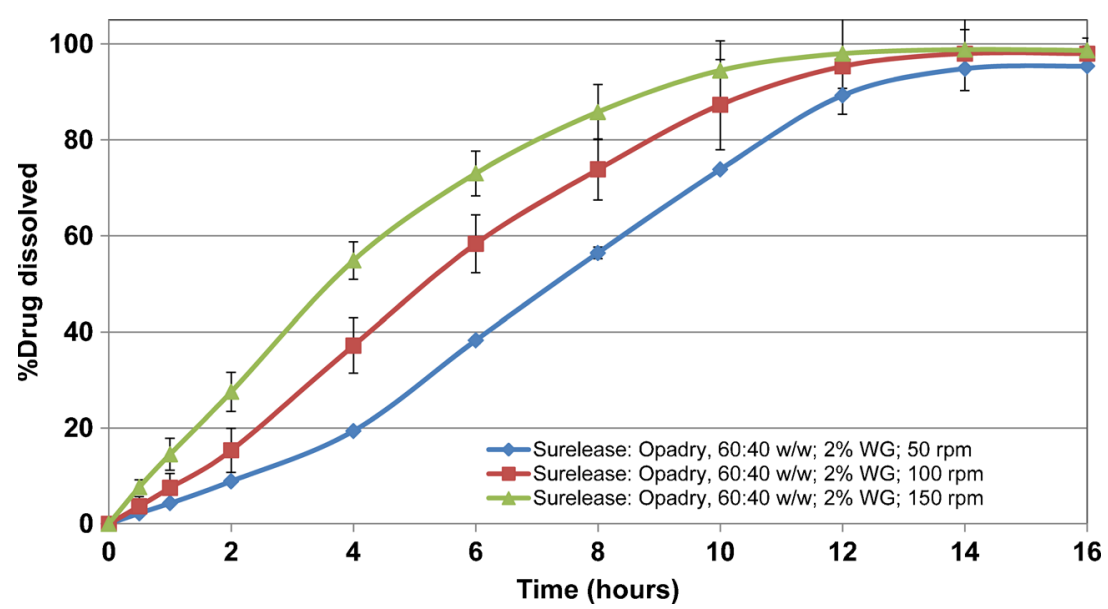

Fig. 7. Drug release profiles of aqueous ethylcellulose coated HCTZ matrix tablets containing lactose in compendial media (coated with Surelease/Opadry, 60:40 w/w, 2\% $w / w$ weight gain (WG)) 


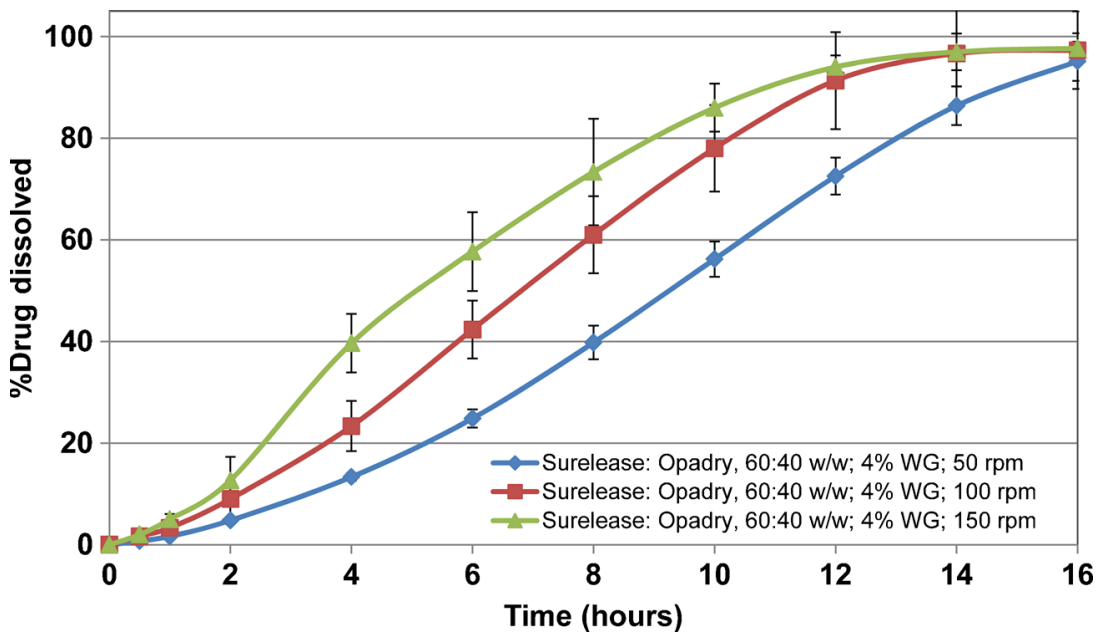

Fig. 8. Drug release profiles of aqueous ethylcellulose coated HCTZ matrix tablets containing lactose in compendial media (coated with Surelease/Opadry, 60:40 w/w, 4\% $w / w$ weight gain (WG))

6 months. The tablets were evaluated at 0,3 , and 6 months for physical properties, assay, and drug release.

\section{RESULTS AND DISCUSSION}

The fate of uncoated and barrier membrane-coated matrix tablets upon exposure to dissolution media is shown in Fig. 2. Upon media uptake, both systems exhibit hydration, swelling, and gel formation followed by tablet erosion. For uncoated matrix tablets, drug release starts to occur from all tablet surfaces upon hydration of tablet peripheries. For ethylcellulose coated tablets, the media permeates through the barrier membrane, results in increased hydrostatic pressure within the system which ultimately leads to the rupture of coating on tablet edges (belly band area). The rupture of barrier membrane occurs in a controlled and consistent fashion, providing only the belly band as the preferential area available for drug release. In general, a lag phase $(0.5-2 \mathrm{~h})$ is observed for drug release profiles from barrier membrane-

Table IV. Comparison of Drug Release Rate and 3-Point Dissolution Data for Uncoated HCTZ Matrix Tablets at Different Agitation Rates (Power Law model), (a) Starch 1500 Formulation; (b) Lactose Formulation

\begin{tabular}{lccc}
\hline & $50 \mathrm{rpm}$ & $100 \mathrm{rpm}$ & $150 \mathrm{rpm}$ \\
\hline (a) Uncoated matrix - Starch 1500 formulation & & \\
$k$ (Kinetic constant) & 4.4 & 8.5 & 13.4 \\
$n$ (Diffusional exponent) & 1.25 & 1.04 & 1.03 \\
$R^{2}$ (Correlation coefficient) & 0.9955 & 0.9940 & 0.9913 \\
$t_{10 \%}(\mathrm{~h})$ & 2.0 & 1.2 & 0.8 \\
$t_{50 \%}(\mathrm{~h})$ & 6.4 & 4.8 & 3.3 \\
$t_{90 \%}(\mathrm{~h})$ & 13.0 & 11.6 & 7.0 \\
(b) Uncoated matrix - lactose formulation & & \\
$k$ (Kinetic constant) & 8.2 & 17.8 & 24.4 \\
$n$ (Diffusional exponent) & 1.01 & 0.75 & 0.64 \\
$R^{2}$ (Correlation coefficient) & 0.9944 & 0.9900 & 0.9910 \\
$t_{10 \%}(\mathrm{~h})$ & 0.6 & 0.2 & 0.2 \\
$t_{50 \%}(\mathrm{~h})$ & 5.4 & 3.6 & 2.8 \\
$t_{90 \%}(\mathrm{~h})$ & 12.0 & 8.0 & 8.0 \\
\hline
\end{tabular}

coated matrices which is associated with the time required for media uptake into the tablets and coating rupture. The noted difference in hydration subsequently leads to a distinct difference in drug release profiles for uncoated and ethylcellulose coated matrix tablets, as discussed in the following sections.

\section{Drug Release from Uncoated Matrix Tablets}

Drug release from uncoated HCTZ matrix tablets containing lactose and Starch 1500, as fillers, in compendial media are illustrated in Figs. 3 and 4. The data points represent the mean value for the evaluated tablets and the error bars signify the standard deviation. The results revealed that drug release from uncoated matrices showed sensitivity to the agitation rates, ranging from 50 to $150 \mathrm{rpm}$. As the agitation rate was increased in the dissolution system, the drug release rate from matrices also increased. Such in vitro behavior may indicate variable in vivo release rate and potential post-prandial effect. Even though the same effect was observed for all uncoated matrices, the tablets containing Starch 1500 showed lower

Table V. Comparison of Drug Release Rate and 3-Point Dissolution Data for Ethylcellulose Coated HCTZ Matrix Tablets at Different Agitation Rates (Zero-Order Kinetics/Linear Equation), (a) Starch 1500 Formulation; (b) Lactose Formulation

\begin{tabular}{lccc}
\hline & $50 \mathrm{rpm}$ & $100 \mathrm{rpm}$ & $150 \mathrm{rpm}$ \\
\hline (a) Coated matrix - Starch 1500 formulation & & \\
$k$ (Release rate, \%/h) & 7.3 & 7.3 & 7.3 \\
$R^{2}$ (Correlation coefficient) & 0.9983 & 0.9983 & 0.9971 \\
$t_{10 \%}(\mathrm{~h})$ & 4.4 & 3.0 & 2.6 \\
$t_{50 \%}(\mathrm{~h})$ & 9.6 & 8.4 & 7.6 \\
$t_{90 \%}(\mathrm{~h})$ & 15.0 & 14.0 & 13.0 \\
$(\mathrm{~b})$ Coated matrix - lactose formulation & & \\
$k($ Release rate, \%/h) & 6.6 & 6.4 & 5.8 \\
$R^{2}($ Correlation coefficient) & 0.9985 & 0.9947 & 0.9994 \\
$t_{10 \%}(\mathrm{~h})$ & 3.6 & 3.8 & 2.8 \\
$t_{50 \%}(\mathrm{~h})$ & 9.2 & 9.8 & 10.4 \\
$t_{90 \%}(\mathrm{~h})$ & 15.8 & 15.8 & 16.2 \\
\hline
\end{tabular}




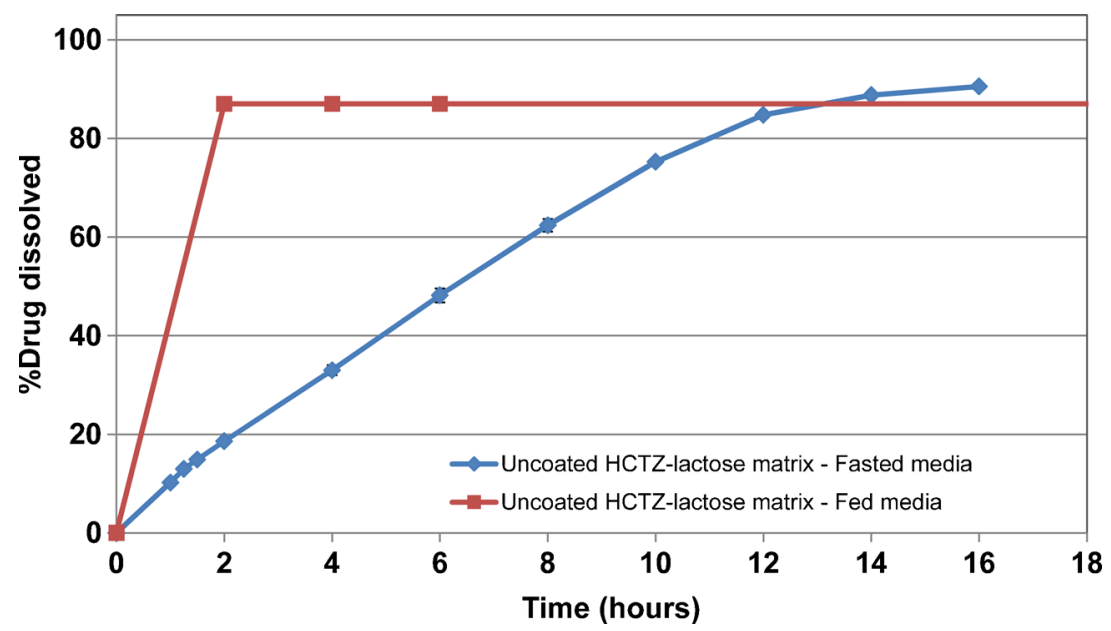

Fig. 9. Dissolution profiles for uncoated HCTZ matrices containing lactose, as filler, in biorelevant fasted and fed media

values of standard error bars compared to those containing lactose, indicating more robust drug release at any given agitation rate.

\section{Drug Release from Ethylcellulose Coated Matrix Tablets}

The drug release from ethylcellulose coated matrix tablets was also evaluated in a similar manner. Figures 5 and 6 show the release profiles for HCTZ matrices coated with aqueous ethylcellulose (Surelease/Opadry, 85:15 w/w) at 2\% $w / w$ weight gain. All matrices showed lag time of approximately $2 \mathrm{~h}$ followed by linear release. The results showed that ethylcellulose coating of HCTZ matrix tablets is effective in reducing the variability of drug release from the tablets. Application of higher weight gains of aqueous ethylcellulose coating (i.e., more than $2 \% \mathrm{w} / \mathrm{w}$ ) resulted in longer lag time (between 2 and $4 \mathrm{~h}$ ) as well as incomplete terminal drug release from all matrix tablets and hence is not recommended.

In order to evaluate the effect of pore former (Opadry) content, the HCTZ matrix tablets containing lactose were coated with Surelease/Opadry combination at 60:40 $w / w$ at
$2 \%$ and $4 \% w / w$ weight gain. The results showed that increasing the pore former content from $15 \%$ to $40 \% \mathrm{w} / \mathrm{w}$ within the ethylcellulose coating resulted in elimination of lag time followed by first-order drug release kinetics. This behavior was more evident at the lower coating weight gain (2\% vs. $4 \%$ $w / w$ ) (Figs. 7 and 8). In addition, the higher level of pore former resulted in more variability in drug release upon increasing the agitation rate. Therefore, based on the obtained results, the ethylcellulose barrier membrane with the pore former content of $15 \% w / w$ was selected as the preferred system.

\section{Drug Release Mechanism for Uncoated and Ethylcellulose Coated Matrix Tablets}

Drug release was characterized and the performance of matrix tablets were compared using the three-point dissolution data $\left(t_{10 \%}, t_{50 \%}, t_{90 \%}\right.$, time required to release $10 \%, 50 \%$, and $90 \%$ of the drug), at different agitation rates, for uncoated and ethylcellulose coated matrices (Tables IV and V). In order to analyze the drug release mechanism, for uncoated matrix

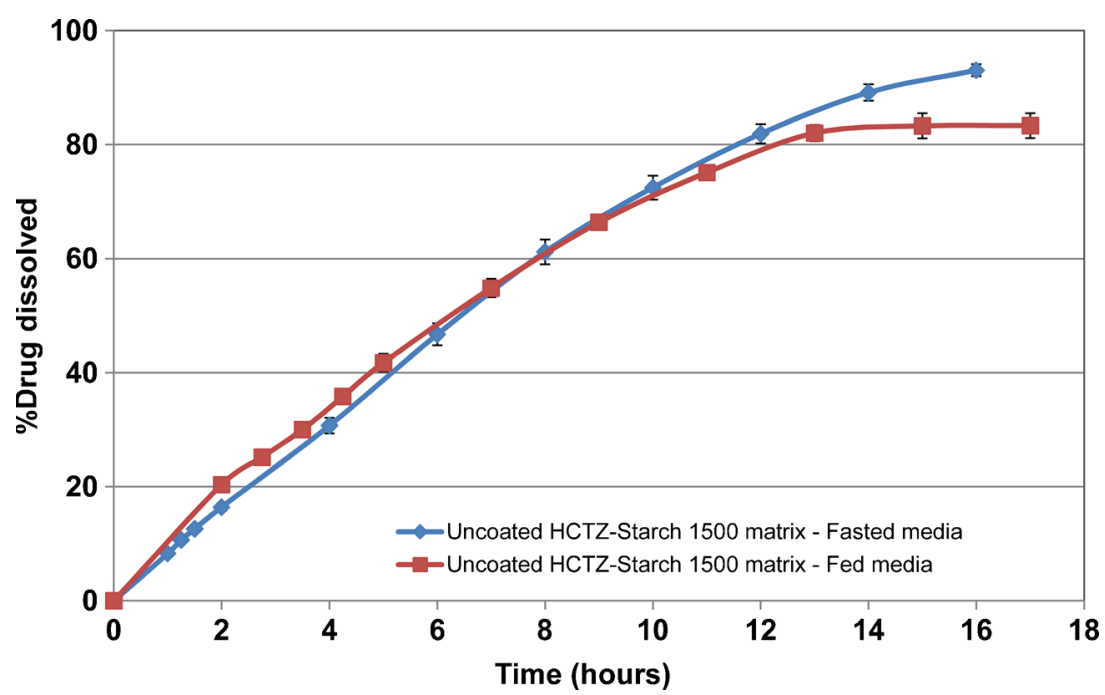

Fig. 10. Dissolution profiles for uncoated HCTZ matrices containing Starch 1500, as filler, in bio-relevant fasted and fed media 


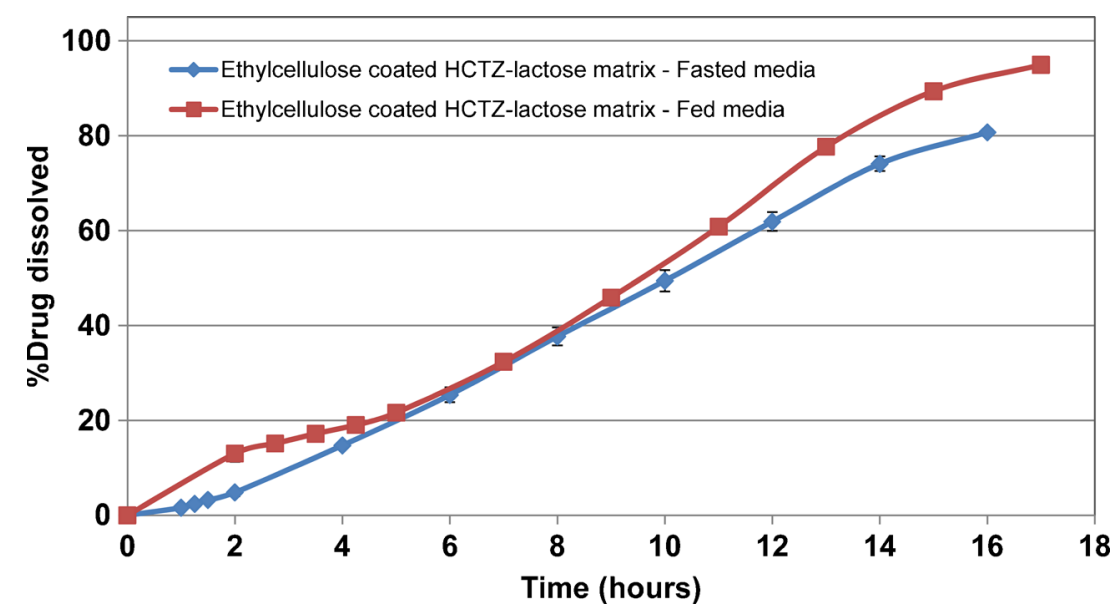

Fig. 11. Dissolution profiles for aqueous ethylcellulose coated HCTZ matrices containing lactose in bio-relevant fasted and fed media (coated with Surelease/Opadry, 85:15 w/w, 2\% $w / w$ weight gain (WG))

tablets, the dissolution data $(\sim 5-85 \%)$ were fitted to the Power Law Model $(17,18)$. For ethylcellulose coated matrices, the drug release profiles in the range of 5-95\% were linear and accordingly the dissolution data provided a suitable fit to zero-order release kinetics. In all instances, the correlation coefficients $\left(R^{2}\right)$ for the data were equal to or greater than 0.99 .

For uncoated matrix tablets containing Starch 1500, increasing the agitation rate resulted in an increase in kinetic constant ( $k$, indicative of drug release rate), in the order of 4.4, 8.5 , and 13.4 for 50,100 , and $150 \mathrm{rpm}$, respectively. The uncoated matrices comprising lactose demonstrated faster release rates of 8.2, 17.8, and 24.4, confirming that the use of Starch 1500 as a filler within the HPMC matrix tablets of HCTZ led to more extended drug release under similar testing conditions. Additionally, comparing the values for $t_{10 \%}$, $t_{50 \%}$, and $t_{90 \%}$ among the matrix tablets confirmed the above results (Table IV). The values of the release exponent $(n$, indicative of drug release mechanism) were in the range of 1.03-1.25 and 0.64-1.01 for matrix tablets containing Starch 1500 or lactose, as fillers, respectively. For cylindrical matrices, Fickian diffusion is represented by $n=0.45$; for non-Fickian release (anomalous behavior), $0.45<n<0.89$; for Case II transport, $n=0.89$; and for Super-Case II transport, $n>0.89$ (17-19). Accordingly, the obtained results revealed a Super-Case II transport for matrix tablets containing Starch 1500 where polymer relaxation is the main contributor to the drug release. In such cases, the release rate accelerates at later stages leading to a more rapid relaxation-controlled transport $(20,21)$. For matrices containing lactose, drug release is governed by a combination of diffusion and erosion, except for when these tablets are subjected to the lower agitation rate of $50 \mathrm{rpm}$ for which the drug release mechanism demonstrates a Super-Case II transport.

For ethylcellulose coated matrix tablets, the release rates $(k)$ at varying agitation speeds were calculated using the linear section of the dissolution profiles (Table V). The results for all coated tablets exhibited less sensitivity to the agitation speed, as evidenced from the drug release rates values of $7.3 \% / \mathrm{h}$ for the tablets containing Starch 1500 , and $6.6-5.8 \% / \mathrm{h}$ when lactose was used as the filler. The calculated values of $t_{10-90 \%}$ were also in agreement with the release rate values, demonstrating less variation compared to the uncoated matrix tablets.

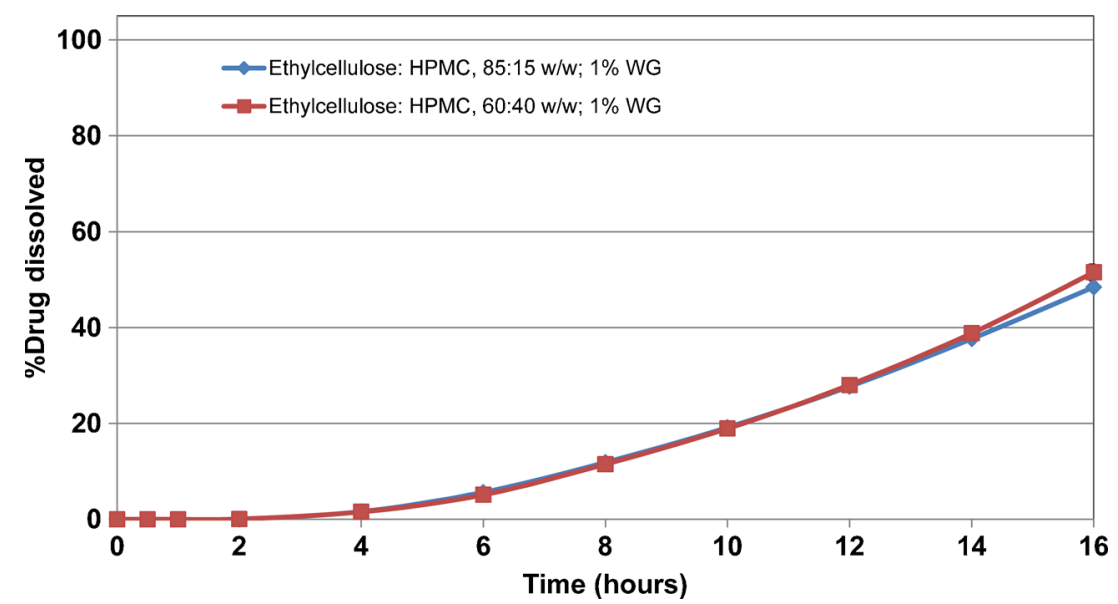

Fig. 12. Drug release profiles of solvent-based ethylcellulose coated HCTZ matrix tablets containing lactose (coated with ETHOCEL 20/METHOCEL E5LV, $1 \%$ w/w weight gain (WG)) 

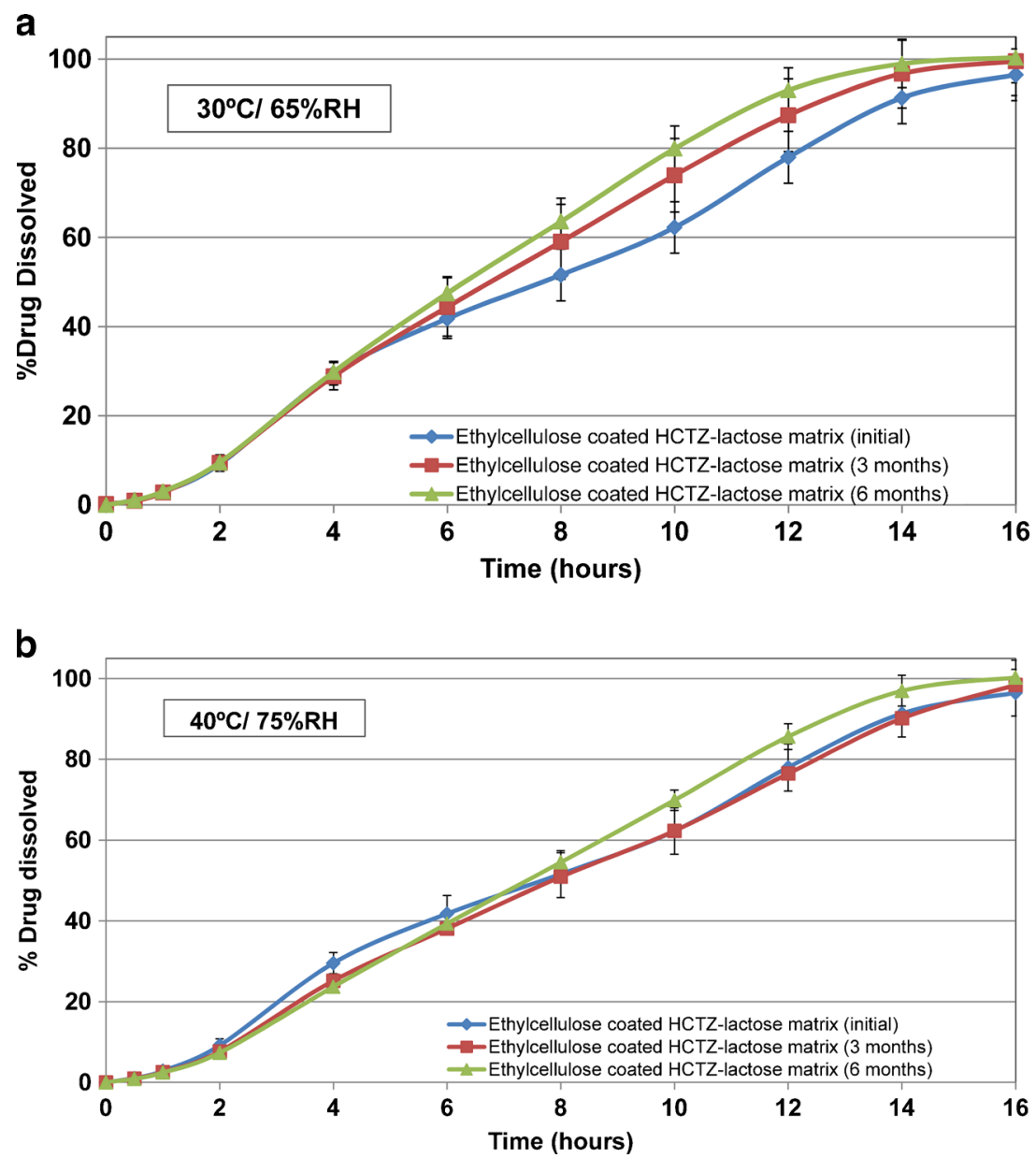

Fig. 13. Drug release profiles of HCTZ matrix tablets containing lactose, as filler, and aqueous ethylcellulose coating (Surelease/Opadry, 85:15 w/w, 2\% $w / w$ weight gain (WG)) after storage in different conditions for 6 months, (a) $30^{\circ} \mathrm{C} / 65 \%$; (b) $40{ }^{\circ} \mathrm{C} / 75 \%$

\section{Drug Release in Bio-Relevant Media}

Furthermore, the HCTZ matrix tablets, uncoated as well as coated with the preferred ethylcellulose coating system (Surelease/Opadry, 85:15 w/w), were subjected to dissolution testing in bio-relevant media. As shown in Fig. 9, the drug release from uncoated matrix tablets containing lactose was in a controlled release fashion in simulated fasted media $(\mathrm{FaS}-$ SIF), while dose dumping was observed under fed conditions (FeSSIF). The faster drug release rate was due to disintegration and rapid erosion of uncoated matrix tablets during exposure to the first phase of the fed media. This presented the challenge of the sink-limiting condition for quantification of the actual amount of the released drug. Further dilution and stirring was used for accurate analysis of the drug.

In comparison, the inclusion of Starch 1500 within the uncoated matrix tablets minimized rapid disintegration and erosion of the uncoated HCTZ matrices and resulted in greater extended drug release which was similar in fasted and fedsimulated media (Fig. 10). This effect could be due to the contribution of Starch 1500 to formation of a stronger gel layer around the matrix tablet $(14,22)$. Application of aqueous ethylcellulose coating resulted in more robust drug release profiles in both fasted and fed media, irrespective of the filler type. The release profiles for HCTZ matrices containing lactose are shown in Fig. 11. Therefore, the application of barrier membrane coating of aqueous ethylcellulose dispersion along with an HPMC-based Opadry system, as a pore former, at $85: 15 w / w$ ratio, and at $2 \%$ weight gain resulted in significant reduction in variability of release and provided zero-order release kinetics. The similarity factors, $f_{2}(23)$, were greater than 60 for all evaluated agitation rates. It was hypothesized that the consistent and uniform breakage of the film coating around the tablet edges was the reason for achieving robust drug release at various agitation rates. The fate of a HCTZ matrix tablet coated with Surelease-Opadry combination over time within the dissolution media is captured as a video (refer to Frame still), demonstrating matrix hydration and swelling followed by rupture of coating layer at the edges of the HCTZ tablet.

\section{Comparative Evaluation of Organic Ethylcellulose Coating}

In comparison, application of solvent-based coating of ETHOCEL 20/METHOCEL E5LV, at 85:15 and 60:40 w/w, on HCTZ matrix tablets at $1 \% w / w$ weight gain resulted in longer lag time $(\sim 5 \mathrm{~h})$ followed by incomplete drug release $(\sim 50 \%$ at $16 \mathrm{~h})$ (Fig. 12). Increasing the pore former level from $15 \%$ to $40 \% w / w$ in the organic coating composition did 

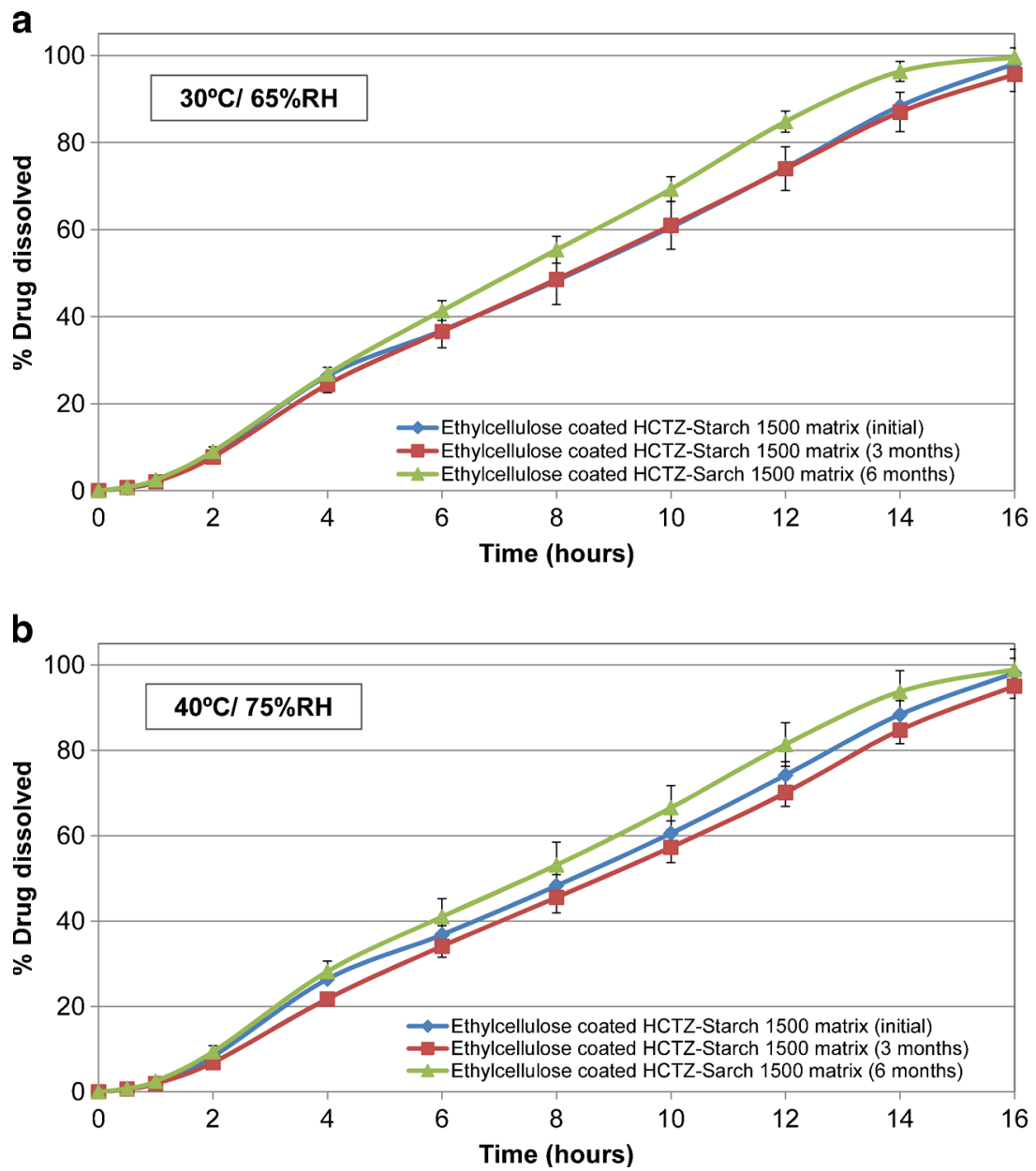

Fig. 14. Drug release profiles of HCTZ matrix tablets containing Starch 1500, as filler, and aqueous ethylcellulose coating (Surelease/Opadry, 85:15 $w / w, 2 \% w / w$ weight gain (WG)) after storage in different conditions for 6 months, (a) $30^{\circ} \mathrm{C} / 65 \%$; (b) $40^{\circ} \mathrm{C} / 75 \%$

not enhance the drug release from such matrices. Increasing the coating weight gain to $2 \% \mathrm{w} / w$ completely shut down the drug release (data not shown). Matrix tablets showed swelling after $16 \mathrm{~h}$ of dissolution testing with no sign of coating rupture. The difference in performance of aqueous versus organic ethylcellulose coated matrices could be attributed to the nature of the film layer. The ethylcellulose coating, when applied organically, can accommodate the swelling matrix to a greater extent compared to aqueous coating and hence, coating rupture and subsequent drug release is prevented. This further confirms the suitability of aqueous ethylcellulose coating of matrix tablets as a preferred barrier membrane coating system, since it provides a consistent rupture pattern at the tablet edges upon exposure to the surrounding media.

\section{Stability Study}

Figures 13 and 14 exhibit the drug release from barrier membrane-coated matrix tablets at the initial time point, as well as upon storage at $30^{\circ} \mathrm{C} / 65 \% \mathrm{RH}$ and $40^{\circ} \mathrm{C} / 75 \% \mathrm{RH}$ conditions, respectively. Aqueous ethylcellulose coated matrix tablets containing lactose or Starch 1500 resulted in similar drug release under exposure to the stability conditions (Table VI). However, the matrices formulated with lactose (soluble filler) resulted in higher variability of drug release as evident from the greater standard error bars in Fig. 13 (average value $=3.9 \%$; range $=0-10.2 \%$ ). Inclusion of Starch 1500 (partially soluble filler) in formulation of HCTZ matrix tablets led to reduction of variability in drug release as evident from the smaller error bars in Fig. 14 (average value $=3.1 \%$, range $=0-7.8 \%$ ). This observation was further confirmed by comparison of $f_{2}$ values (Table VI), where ethylcellulose coated matrices containing Starch 1500 demonstrated greater $f_{2}$ values compared to the tablets containing lactose. This indicates that inclusion of Starch 1500 as filler results in more robust drug release from the hydrophilic matrices. The drug

Table VI. Comparison of Similarity Factors $\left(f_{2}\right)$ for Aqueous Ethylcellulose Coated HCTZ Matrix Tablets

\begin{tabular}{lccc}
\hline Stability condition & Duration & Starch 1500 & Lactose \\
\hline $40^{\circ} \mathrm{C} / 75 \% \mathrm{RH}$ & 3 months & 85 & 77 \\
$30^{\circ} \mathrm{C} / 65 \% \mathrm{RH}$ & 6 months & 65 & 64 \\
& 3 months & 94 & 60 \\
& 6 months & 63 & 52 \\
\hline
\end{tabular}

Release profiles for each filler at initial time point was considered as reference 
release profiles from the tablets, containing either filler, remained similar after storage for 6 months, when compared to their respective dissolution profiles obtained at the initial time point $\left(f_{2}>50\right.$ in both cases; Table VI).

\section{CONCLUSIONS}

The application of a barrier membrane coating system consisting of aqueous ethylcellulose dispersion (Surelease) and an HPMC-based Opadry system, as a pore former, was found to be a promising strategy to obtain robust and consistent drug release profiles from hydrophilic matrix tablets of hydrochlorothiazide. The coated matrices showed minimal sensitivity to varying agitation rates and simulated post-prandial effects. The barrier membrane weight gain and inclusion level of the pore former within the coating are critical in achieving consistent drug release profiles which may further resist highly variable mechanical forces acting on matrix formulations in fed and fasted states. Aqueous ethylcellulose coated matrices, with either Starch 1500 or lactose as fillers, provided consistent and stable drug release profiles, irrespective of the storage conditions. Use of Starch 1500, in particular, contributed to enhanced robustness of the matrix tablets. Such a formulation strategy may provide options for the development of dosage forms where zero-order drug release kinetics is desired. This study, therefore, highlighted various approaches which could be used either alone or in combination to successfully formulate robust hydrophilic matrices of a low-soluble drug with minimal susceptibility to drug release variability.

\section{ELECTRONIC SUPPLEMENTARY MATERIAL}

Below is the link to the electronic supplementary material. ESM 1 Frame still (video). Fate of barrier membrane-coated HCTZ matrix tablets containing lactose, as filler, and aqueous ethylcellulose coating (Surelease/Opadry, 85:15 w/w, 2\% w/w weight gain (WG)) in dissolution media over time (WMV $2489 \mathrm{~kb}$ )

Open Access This article is distributed under the terms of the Creative Commons Attribution License which permits any use, distribution, and reproduction in any medium, provided the original author(s) and the source are credited.

\section{REFERENCES}

1. Rajabi-Siahboomi AR, Jordan MP. Slow release HPMC matrix systems. Eur Pharm Rev. 2000;5:21-3.

2. Tiwari SB, Rajabi-Siahboomi AR. Extended-release oral drug delivery technologies: monolithic matrix systems. In: Jain KK, editor. Drug delivery systems, methods in molecular biology, vol. 437. Totowa: Humana Press; 2008. p. 217-43.

3. Using METHOCEL ${ }^{\mathrm{TM}}$ cellulose ethers for controlled release of drugs in hydrophilic matrix systems. http://msdssearch.dow.com/ PublishedLiteratureDOWCOM/dh_0379/0901b803803797ad.pdf? filepath=methocel/pdfs/noreg/198-02075.pdf\&fromPage=GetDoc. Accessed 2 Dec 2013.
4. Abrahamsson B, Alpsten M, Bake B, Larsson A, Sjögren J. In vitro and in vivo erosion of two different hydrophilic gel matrix tablets. Eur J Pharm Biopharm. 1996;46(1):69-75.

5. Abrahamsson B, Alpsten M, Bake B, Jonsson UE, ErikssonLepkowska M, Larsson A. Drug absorption from nifedipine hydrophilic matrix-extended release (ER) tablet-comparison with an osmotic pump tablet and effect of food. J Control Release. 1998;52:301-10.

6. Abrahamsson B, Roos K, Sjögren J. Investigation of prandial effects on hydrophilic matrix tablets. Drug Dev Ind Pharm. 1999;25(6):765-71.

7. Abrahamsson B, Pal A, Sjoberg M, Carlsson M, Laurell E, Brasseur JG. A novel in vitro and numerical analysis of shear-induced drug release from extended release tablets in the fed stomach. Pharm Res. 2005;22(8):1215-26.

8. Dressman JB, Amidon G, Reppas C, Shah VP. Dissolution testing as a prognostic tool for oral drug absorption: immediate release dosage forms. Pharm Res. 1998;15:11-22.

9. Boni JE, Brickl RS, Dressman JB, Pfefferle ML. Instant FaSSIF and FeSSIF-biorelevance meets practicality. Dissolution Technol. 2009;16(3):41-6.

10. Schaich M, Kloefer B, Leigh M. Dissolution test results showing biorelevant media made from SIF powder original are the same as media prepared using methylene chloride. http://ww.biorelevant.com/ site_media/upload/documents/Biorelevant-dissolution-tests.pdf. Accessed 3 Oct 2013.

11. Dressman JB, Kramer J. Pharmaceutical dissolution testing. Boca Raton: Taylor \& Francis Group; 2005.

12. Klein S. Predicting food effects on drug release from extendedrelease oral dosage forms containing a narrow therapeutic index drug. Dissolution Technol. 2009;16(3):28-38.

13. Asare-Addo K, Levina M, Rajabi-Siahboomi AR, Nokhodchi A. Effect of ionic strength and $\mathrm{pH}$ of dissolution media on theophylline release from hypromellose matrix tablets-apparatus USP III, simulated fasted and fed conditions. Carbohydr Polym. 2011;86(1):85-93.

14. Levina M, Rajabi-Siahboomi AR. The influence of excipients on drug release from hydroxypropyl methylcellulose matrices. J Pharm Sci. 2004;93:2746-54.

15. Ayres JW. Coated, platform-generating tablet. 2004. US Patent 6,720,005 B1.

16. Avdeef A, Berger CM, Brownell C. pH-metric solubility. 2: correlation between the acid-base titration and the saturation shakeflask solubility-pH methods. Pharm Res. 2000;1:85-9.

17. Korsmeyer RW, Gurny R, Doelker E, Buri P, Peppas NA. Mechanisms of solute release from porous hydrophilic polymers. Int J Pharm. 1983;15(1):25-35.

18. Ritger PL, Peppas NA. A simple equation for description of solute release II. Fickian and anomalous release from swellable devices. J Control Release. 1987;5:37-42.

19. Siepmann J, Peppas NA. Modeling of drug release from delivery systems based on hydroxypropyl methylcellulose (HPMC). Adv Drug Deliv Rev. 2001;48(2-3):139-57.

20. Wu BJ, Wei XL, Lu Y, Wu W. Optimization of the biphasic release of indomethacin from HPMC/pectin/calcium chloride matrix tablet by response surface methodology. J Chin Pharm Sci. 2008;17:285-90.

21. Rapolu K, Dharani S, Yamsani MR. Preparation and evaluation of multiple-unit gastro retentive floating drug delivery system for ondansetron hydrochloride based on gas formation technique. Int J Pharm. 2012;2(1):46-54.

22. Myles EB, Melia CD, Levina M, Rajabi-Siahboomi AR. The effect of diluent type on the robustness of HPMC matrices to ionic challenges, 33rd annual meeting and exposition of the Controlled Release Society. 2006.

23. Moore JW, Flanner HH. Mathematical comparison of curves with an emphasis on in vitro dissolution profiles. Pharm Technol. 1996;20(6):64-74. 